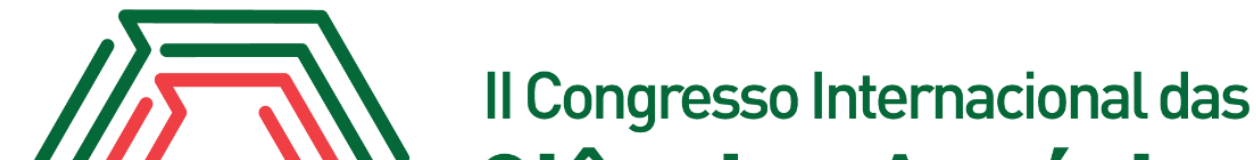 Ciências Agrárias COINTER - PDVAgro 2017
}

\section{EFEITO DA ADUBAÇÃO ORGÂNICA, NA PRODUÇÃO DE RÚCULA, EM SOLO COBERTO COM MULCHING E SEM COBERTURA MORTA}

\author{
Apresentação: Pôster
}

\begin{abstract}
Martiliana Mayani Freire ${ }^{1}$; Ellen Rachel Evaristo de Morais ${ }^{2}$; Eric Georg Morais ${ }^{3}$; Anna Yanka de Oliveira Santos ${ }^{4}$; Ermelinda Maria Mota Oliveira ${ }^{5}$
\end{abstract}

\section{Introdução}

O uso da água residuária da mandioca (manipueira) como fertilizante orgânico é uma alternativa viável para adubação da rúcula (Eruca sativa Miller), que é uma das hortaliças em destaque no mercado nacional, devido a manipueira possuir características de biofertilizante e grandes teores de nutrientes, principalmente, o potássio, o nitrogênio e o fósforo.

Dentre as diversas técnicas que vêm sendo implantadas no cultivo de hortaliças, destaca-se a utilização de cobertura morta, ou mulching por apresentar baixo custo e proporcionar ao consumidor a entrega de produtos de maior qualidade, visto que evita o contato direto da hortaliça com o solo (CARVALHO et al., 2005).

Tendo em vista por adiante à adoção de práticas sustentáveis em atividades agrícolas, o presente trabalho teve como objetivo avaliar a influência do mulching preto na produtividade da rúcula a doses crescentes de manipueira.

\section{Fundamentação Teórica}

A água residuária da mandioca apresenta-se como ferramenta sustentável para redução da utilização de fertilizantes químicos por possuir características de fertilizantes, sendo também utilizada no controle de pragas como os pulgões, causando a drástica redução populacional desses

\footnotetext{
${ }^{1}$ Graduada em Agronomia, Universidade Federal do Rio Grande do Norte, martilianafreire11@gmail.com

${ }^{2}$ Graduanda em Agronomia, Universidade Federal do Rio Grande do Norte, ellen-racheel@hotmail.com

${ }^{3}$ Graduando em Agronomia, Universidade Federal do Rio Grande do Norte, ericmoraais@hotmail.com

${ }^{4}$ Graduanda em Agronomia, Universidade Federal do Rio Grande do Norte, annayanka12@hotmail.com

${ }^{5}$ Professora Doutora, Universidade Federal do Rio Grande do Norte, ermelindasolos@gmail.com
} 
insetos quando aplicada uma concentração de ação letal (JESUS \& MENDONÇA, 2012). Além disso, ao aplicar a água residuária da mandioca como biofertilizante em hortaliças, o produtor está beneficiando a lavoura, por utilizar um resíduo rico em nutrientes que antes era desperdiçado e despejado no solo e evitando um passivo ambiental, que é a poluição do solo e/ou da água. Esta poluição ocorre devido a produção e deposição "de grandes volumes deste líquido, provocando condições de insalubridade na população, prejudicando à saúde e a economia desta atividade" (SANTOS, 2009 apud CANÁRIO, 2015).

A técnica de cobertura de solo, utilização do mulching preto, também se apresenta como potencial na conservação e melhor utilização dos solos agrícolas, principalmente em regiões sensíveis aos processos erosivos, como áreas litorâneas e quentes pois este produto sintético promove a menor perda de solo por erosão e de água por evaporação. Além disso, o uso de cobertura morta no solo diminui as oscilações da temperatura do solo (BRAGAGNOLO \& MIELNICZUK, 1990 apud CARVALHO et al., 2005), reduz a perda de nutrientes por lixiviação (CARTER \& JOHNSON, 1988 apud CARVALHO et al., 2005) e melhora os atributos físicos e químicos do solo (FIALHO et al., 1991 apud CARVALHO et al., 2005).

Dessa forma, o produtor proveniente da agricultura familiar pode melhorar sua qualidade de vida, reduzir custos, aumentar o lucro e reduzir seus passivos ambientais.

\section{Metodologia}

O experimento foi realizado na área de experimentação agroecológica do Grupo de Estudo em Solos (GESOLO) da Unidade Acadêmica Especializada em Ciências Agrárias da Universidade Federal do Rio Grande do Norte, localizada na Escola Agrícola de Jundiaí (EAJ), no período de setembro a novembro de 2016, situado na Latitude Sul 5 53' 35.12" e Longitude Oeste $35^{\circ} 21^{\prime}$ 47.03".

O solo da área de implantação do experimento é classificado como Neossolo Flúvico. Segundo a classificação de Koppen, o clima da região está compreendido entre os tipos As' e BSh', apresentando uma estação chuvosa (verão) e quente, e outra, caracterizada pelo inverno seco (IDEMA, 2013).

A manipueira utilizada foi oriunda do distrito do Cobé, município de Vera Cruz/RN, na Casa de Farinha Santa Helena e analisada quimicamente no Laboratório da EMPARN. Ao receber o 
resultado da análise, foram calculadas as doses ideais do biofertilizante para cada tratamento trabalhado. Foram implantados dois experimentos concomitantemente, de modo que um foi executado sem cobertura morta e o outro, com mulching preto, como cobertura morta.

Utilizou-se a variedade rúcula cv. cultivada, quatro doses de manipueira $\left(0,60,90\right.$ e $120 \mathrm{~m}^{3}$ $\left.\mathrm{ha}^{-1}\right)$, com quatro repetições para cada tratamento. Cada parcela, de cada ensaio, era constituída por 16 plantas, sendo as 4 centrais, a parcela útil. A aplicação dos tratamentos e cobertura do solo com o mulching foram realizadas 10 dias antes do transplantio, devido a manipueira possuir na sua composição ácido cianídrico. As variáveis analisadas foram: altura de planta, massa fresca e massa seca. A colheita da rúcula ocorreu 35 dias após o transplantio.

Os dados foram submetidos à análise de variância, teste t a $1 \%$ de significância, como teste estatístico, a fim de verificar o efeito significativo do fator sobre as variáveis resposta.

\section{Resultados e Discussões}

As características avaliadas apresentaram efeito significativo para as doses de manipueira, tanto no ensaio sem cobertura de solo (A), quanto no ensaio com cobertura morta (B).

Obteve-se, para o fator manipueira sob solo sem cobertura, ajuste ao modelo polinomial quadrático de regressão para a variável altura de plantas. E, ao avaliar o fator manipueira com cobertura morta, observou-se ajuste ao modelo linear de regressão (figura 1).

Figura 1: Altura de plantas de rúcula, em solo sem cobertura e coberto com mulching, em função das doses de manipueira. Fonte: própria.
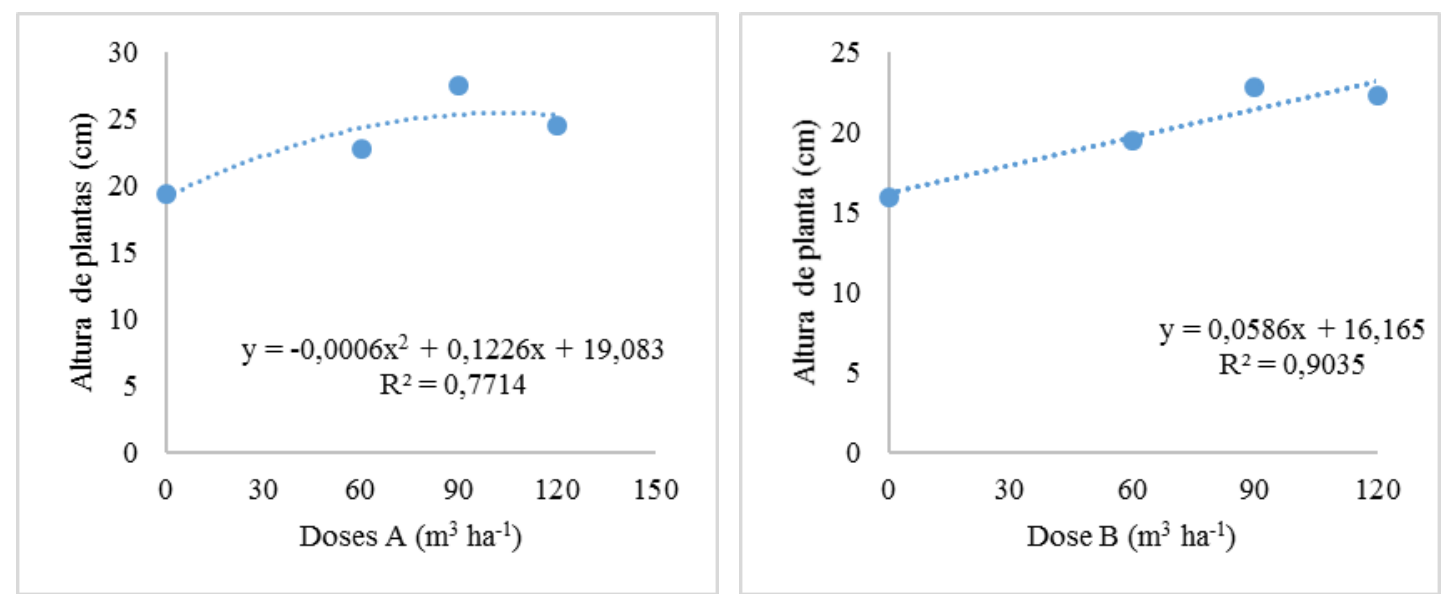

Corroborando os resultados, Canário (2015), ao avaliar a aplicação de doses crescentes de manipueira no solo na cultura da rúcula (Eruca sativa Miller), apontou maiores valores de altura de 
planta para a dose de $90 \mathrm{~m}^{3} \mathrm{ha}^{-1}$.

A figura 2 mostra o efeito das dosagens manipueira no aumento de produção de massa fresca para as duas condições em questão. Observou-se um comportamento linear para as doses de manipueira, obtendo maiores médias na dose de $120 \mathrm{~m}^{3} \mathrm{ha}^{-1}$.

Figura 1: Produção de massa fresca da parte aérea de rúcula, em solo sem cobertura e coberto com mulching, em função das doses de manipueira. Fonte: própria.
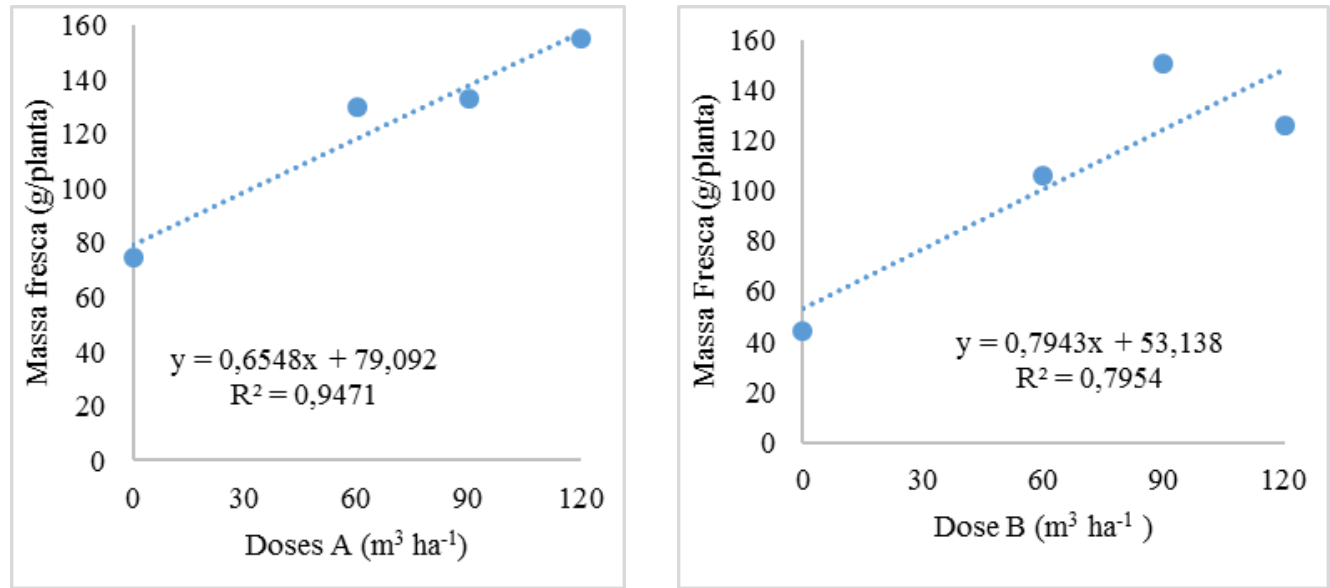

Lucena-Cavalcante et al. (2012); Silva (2010), observaram em estudo um acúmulo de massa fresca, à medida que aumentou as doses de manipueira até o tratamento de dose máxima de manipueira, obtendo melhor massa fresca.

A figura 3 apresenta o efeito das dosagens de manipueira no incremento de massa seca aos ensaios solo sem cobertura morta (A) e, solo com cobertura morta (B). Observou-se ajuste ao modelo linear de regressão, com maiores valores médios de massa seca na dose de $120 \mathrm{~m}^{3} \mathrm{ha}^{-1}$.

Figura 3: Acúmulo de massa seca da parte aérea de rúcula, em solo sem cobertura morta e coberto com mulching, em função das doses de manipueira. Fonte: própria.
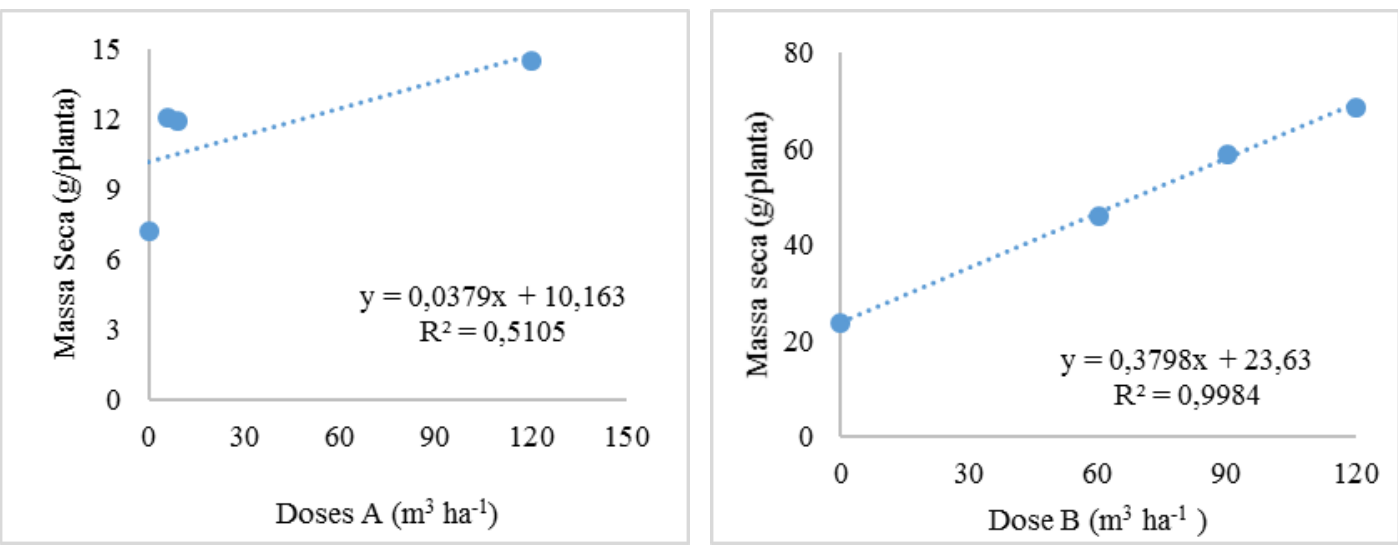

Lima (2010), verificou um comportamento quadrático positivo para o acúmulo de massa 
seca, observando o valor máximo alcançado para a dose de $400 \mathrm{~mL}$ de manipueira. A partir dessa dose, houve um decréscimo para o acúmulo de massa seca.

\section{Conclusões}

O uso da manipueira é indicado até a dose máxima de $120 \mathrm{~m}^{3} \mathrm{ha}^{-1}$ e em associação com a cobertura de solo aplicada neste estudo.

Foi constatado ainda que o uso desta cobertura no solo minimizou significativamente o tempo de trabalho com os tratos culturais durante o plantio, um fator desejável para grandes superfícies.

\section{Referências}

CANÁRIO, T. M. F. Resposta da rúcula (Eruca sativa) a doses crescentes de água residuária da mandioca em comparação a adubação mineral. 2015. 55 p. Monografia (Graduação em Agronomia) - Escola Agrícola de Jundiaí, Unidade Acadêmica Especializada em Ciências Agrárias da Universidade Federal do Rio Grande do Norte, Macaíba, 2015.

CARVALHO, J. E. et al. Cobertura morta do solo no cultivo de alface cv. Regina 2000, em JiParaná/RO. Rev. Ciênc. Agrotec., Lavras, v. 29, n. 5, p. 935-939, 2005.

INSTITUTO DE DESENVOLVIMENTO SUSTENTÁVEL E MEIO AMBIENTE DO RIO GRANDE DO NORTE - IDEMA. Perfil do seu município, Macaíba-RN, 2013. Disponível em <http://adcon.rn.gov.br/ACERVO/idema/DOC/DOC000000000016679.PDF> Acesso em 15 out. 2016

JESUS, S. C. P. de; MENDONÇA, F. A. C. de. Atividade do extrato aquoso da mandioca sobre a mortalidade e reprodução do pulgão da couve. Revista Brasileira de Ciências Agrárias, p. 826830, 2012.

LIMA, N. S. Uso da manipueira como biofertilizante na cultura da alface. 2010. 34 p. Trabalho de Conclusão de Curso (Graduação em agronomia) - Universidade Federal de Alagoas, Centro de Ciências Agrárias, Rio Largo, Alagoas.

LUCENA-CAVALCANTE, I. H. Biochar no substrato para produção de mudas de maracujazeiro amarelo. Revista de la Facultad de Agronomía, La Plata, p. 41-47, 2012.

SILVA, A. V. L. da. Uso de manipueira como biofertilizante na cultura da rúcula (Eruca sativa Miller) cultivada em estufa. 2010. 40 p. Trabalho de Conclusão de Curso (Graduação em Agronomia) - Universidade Federal De Alagoas, Centro De Ciências Agrárias Curso De Agronomia, Rio Largo, Alagoas. 